\title{
Regional model simulation of the hydrometeorological effects of the Fucino Lake on the surrounding region
}

\author{
B. Tomassetti ${ }^{1}$, F. Giorgi ${ }^{2}$, M. Verdecchia ${ }^{1}$, and G. Visconti ${ }^{1}$ \\ ${ }^{1}$ CETEMPS, Department of Physics, University of L'Aquila, Via Vetoio, 67010 Coppito L'Aquila, Italy \\ ${ }^{2}$ Abdus Salam International Centre for Theoretical Physics, Strada Costiera 11, 34014 Trieste, Italy
}

Received: 8 April 2002 - Revised: 7 January 2003 - Accepted: 9 April 2003

\begin{abstract}
The drainage of the Fucino Lake of central Italy was completed in 1873 , and this possibly caused significant climatic changes over the Fucino basin. In this paper we discuss a set of short-term triple-nested regional model simulations of the meteorological effects of the Fucino Lake on the surrounding region. We find that the model simulates realistic lake-breeze circulations and their response to background winds. The simulations indicate that the lake affects the temperature of the surrounding basin in all seasons and precipitation in the cold season, when cyclonic perturbations move across the region. Some effects of the lake also extend over areas quite far from the Fucino basin. Our results support the hypothesis that the drainage of the lake might have significantly affected the climate of the lake basin. However, longer simulations and further development in some aspects of the model are needed, in order to provide a more statistically robust evaluation of the simulated lake-effects.
\end{abstract}

Key words. Hydrology (anthropogenic effects) - Meteorology and atmospheric dynamics (climatology; mesoscale meteorology)

\section{Introduction}

The Fucino Lake, with an area of about 150 square kilometers, was the largest reservoir of fresh water in the Abruzzi region of central Italy until it was drained towards the end of the nineteenth century (1873). A first attempt to drain the lake was made by the Roman Emperor Claudius around 50 B.C. About 30.000 workers excavated a channel that provided the lake with an artificial emissary. However, after some time the channel was clogged with detritus and the lake returned to its original level. One of the reasons for draining the Fucino Lake was that, because of its shallowness, the lake level would change rapidly in response to changes in climatic forcings. These changes in lake levels produced consider-

Correspondence to: $\mathrm{B}$. Tomassetti

(Barbara.Tomassetti@aquila.infn.it) able damage to the people living on the lake's shores and to the agricultural activities that flourished in the surrounding basin. The main hydrological input for the lake was autumn and winter rainfall. Precipitation transported erosion debris from the hills surrounding the lake, resulting in muddy lake waters and in the generation of extensive marsh areas. The drainage of the lake would, therefore, allow fora substantial increase in the availability of areas usable for agricultural purposes.

The water level of the lake was sensitive to climatic variability. It has been established (Giraudi, 2001) that the largest increase in lake level and area occurred towards the end of the last glacial period, about 20000 years ago. Another large change in lake level has been dated at about 3000 years ago (Giraudi, 2001). Indirect evidence shows that before the drainage of the lake the climate of the region was milder than in present conditions. The lake basin was used by the Romans as a summer retreat and the vegetation surrounding the lake consisted mostly of olive trees and vineyards (Burri, 1994).

Observed data for temperature and precipitation prior to the lake drainage are very sparse and often not reliable. Daily precipitation data are available for the period 1854-1873, while decadal average temperature data are available from 1866 to 1906 . The main sources of this data are the important contribution by Brisse and De Rotrou (1883) and the Italian Ministry of Public Works. Analysis of these data sets (e.g. Ruggeri, 1982) suggests that the annual averages of temperature and precipitation have not changed significantly in the area compared to other regions of central Italy. However, the data also indicate an apparent increase in extreme phenomena over the basin after the drainage of the lake, with more intense precipitation during winter months and decreased precipitation during the summer.

It is well known that large inland bodies of water can affect the hydroclimatology of the surrounding regions. For example, much of the wintertime snowfall over the eastern coastal regions of the Great Lakes of the United States is due to lake-effects (e.g. Changnon and Jones, 1972; Eichenlaub, 


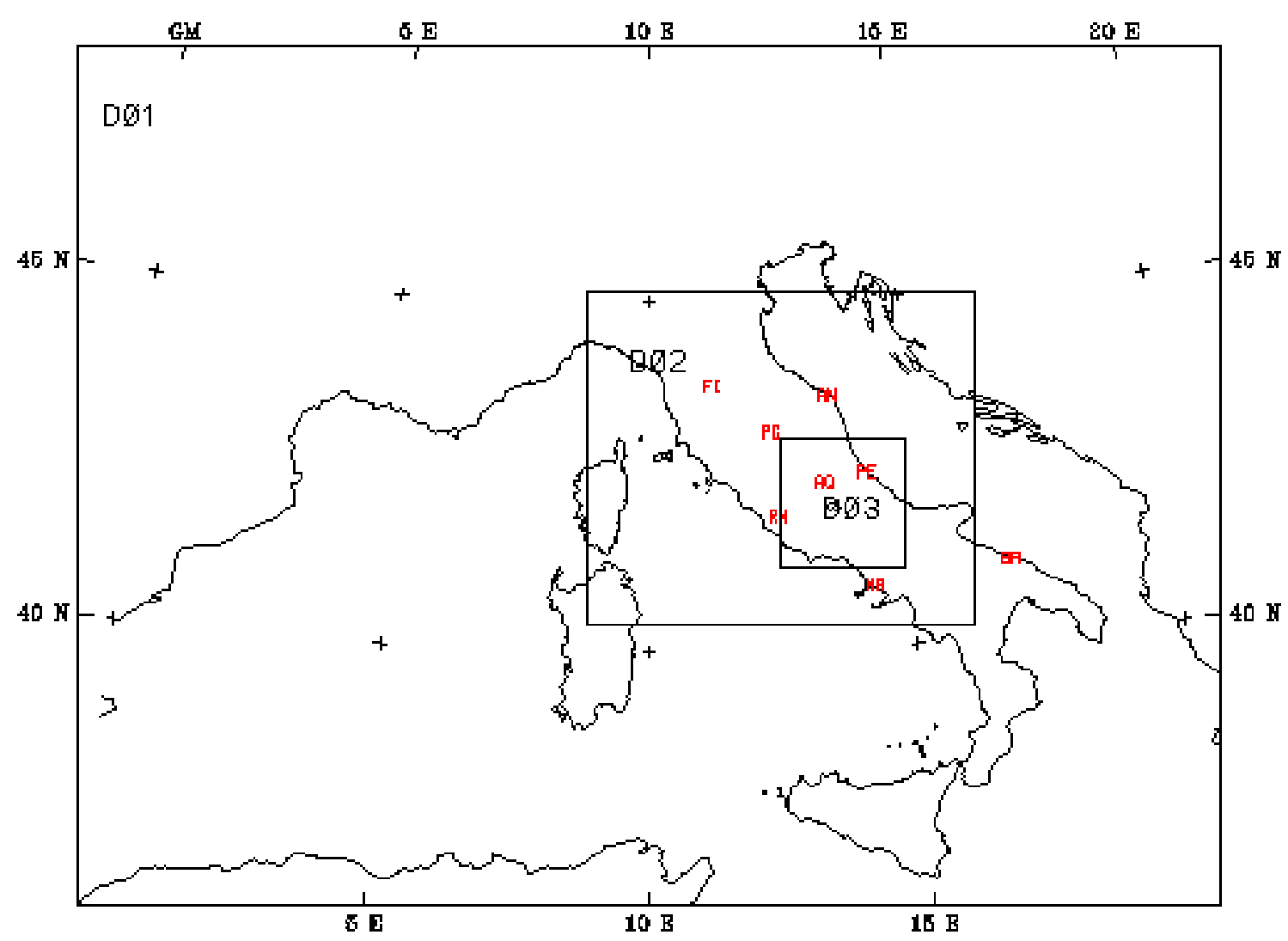

Fig. 1. Triple-nested domain used for the simulations.

1979). Smaller lakes have also been observed to influence local climate characteristics. An example is the lake Okeechobee of Southern Florida, which affects the occurrence of thunderstorm activity in connection with the generation of lake-breeze circulations (e.g. Pielke, 1974). The local hydrometeorological effects of Lake Kinneret in Israel (also known as the "Sea of Galilee") have been investigated by Assouline and Mahrer (1995) and Avissar and Pan (1999). They document the occurrence of lake breezes which interact with the Mediterranean sea breeze and the synoptic scale weather systems that travel across the region. Complex daily and seasonal circulation regimes induced by the interaction of synoptic systems, topographic slope circulations and lake breezes have also been investigated by Bitan (1974) for the northwest section of the Dead Sea and by McGowan et al. (1995) for the Lake Tekapo in the Southern Alps of New Zealand.

All these studies suggest that it is possible that some of the climatic changes over the Fucino basin suggested by the data, as well as the indirect evidence mentioned above could be at least partially explained by the drainage of the lake. The Fucino might thus provide a good example of a regional climate impact by a major anthropogenic modification of the land surface.

Based on these premises, a research program as been initiated at the University of L'Aquila aimed at investigating the long-term regional climatic effects of the drainage of the Fucino Lake via a series of regional climate simulations. As part of the first stages of this research program, in this work a limited area atmospheric model has been adapted to the Abruzzi region using a multiple nesting approach, and a number of test cases have been completed in order to evaluate the model's capability to simulate the lake's hydrometeorological effects. The evaluation of the model is carried out by intercomparing simulations with and without the presence of the lake. Note that, although this work focuses on the Fucino basin, it should be viewed within the broader context of the issue of the regional climatic effects associated with land-use modifications by human activities.

The model and experiment set up is first briefly described in Sect. 2. Results are then discussed in Sect. 3 and final considerations are presented in Sect. 4.

\section{Model and experiment design}

The model used in this work is the NCAR/Pennsylvania State University mesoscale model MM5 (Dudhia, 1993; Grell et al., 1994). This is a primitive equation, $\sigma$ vertical coordinate model used by a broad research community for a variety of applications. The MM5 includes a number of different options of physical parameterizations. For our experiments we use the Kain-Fritsch cumulus cloud scheme (Kain and Fritsch, 1990) along with an explicit cloud water/ice scheme 
(Grell et al., 1994). Radiative transfer is described via the simplified scheme described Grell et al. (1994) and boundary layer physics is represented using the MRF scheme (Troen and Mahrt, 1986). For land surface processes we use the standard MM5 scheme, in which the surface temperature is calculated via a force-restore method and evaporation is computed using a fixed moisture availability parameter (ratio of actual to potential evaporation) dependent on the surface vegetation type. The model uses 24 unevenly spaced $\sigma$ levels.

Figure 1 shows the model triple-nested domain used in the experiments. The outer domain covers Italy and the surrounding regions at a grid interval of $27 \mathrm{~km}$, the intermediate domain covers central Italy at a $9 \mathrm{~km}$ grid interval, while the inner domain encompasses the Abruzzi region at a $3 \mathrm{~km}$ grid interval. The different domains are nested in a two-way mode as described, for example, by Zhang et al. (1986). Note that in the inner domain, no cumulus parameterization is employed, and precipitation is directly calculated via the explicit cloud scheme. This is because at the $3 \mathrm{~km}$ grid point spacing the scale separation assumption underlying most cumulus cloud schemes loses its validity. The MM5 in this domain configuration is used for operational forecasts at the University of L'Aquila and has shown good performance in reproducing synoptic and mesoscale circulations over the region (Paolucci et al., 1999; http://cetemps.aquila.infn.it/mm52web). In this paper we only discuss results from the inner domain.

Figure 2 shows in more detail the topography and land-use of the inner domain, as well as the area covered by the Fucino Lake. Also shown in the figure is a sub-region surrounding the lake that we use for more detailed analysis in Sect. 3.4. As can be seen from Fig. 2, central Italy is characterized by quite complex topographical features of the central Appennines chain. In particular, the lake is surrounded by relatively steep mountain systems, the chain of Mount Sirente to the northeast, the Mount Velino and Tre Monti to the northwest, Mount Pianeccia to the east and Mount Fontecchia to the south. As a result, the effects of the lake can be expected to interact with the topographic forcing of the surrounding region. Note that at the resolution of the inner domain, 16 grid points are necessary to describe the lake area (see Fig. 2b).

In order to run the model, lake surface temperatures are needed. Unfortunately, no historical data of lake temperature are available for the Fucino Lake. Therefore, as a proxy for the Fucino Lake surface temperatures we used observed temperatures for the Lake Trasimeno which, like Fucino, is located in central Italy and has a similar size. From these observations we estimated a lake surface temperature for each of the cases described below and assigned all the lake grid points the same surface temperature. We also carried out some sensitivity experiments (not discussed in this paper) in which the temperature of the lake varied by a few degrees and found that our main conclusions did not change. Alternatively, a coupled lake model could be used to simulate the lake temperatures. However, this would need a careful validation of the lake model and subsequent adaptation to the Fucino basin environment. Given the preliminary nature of

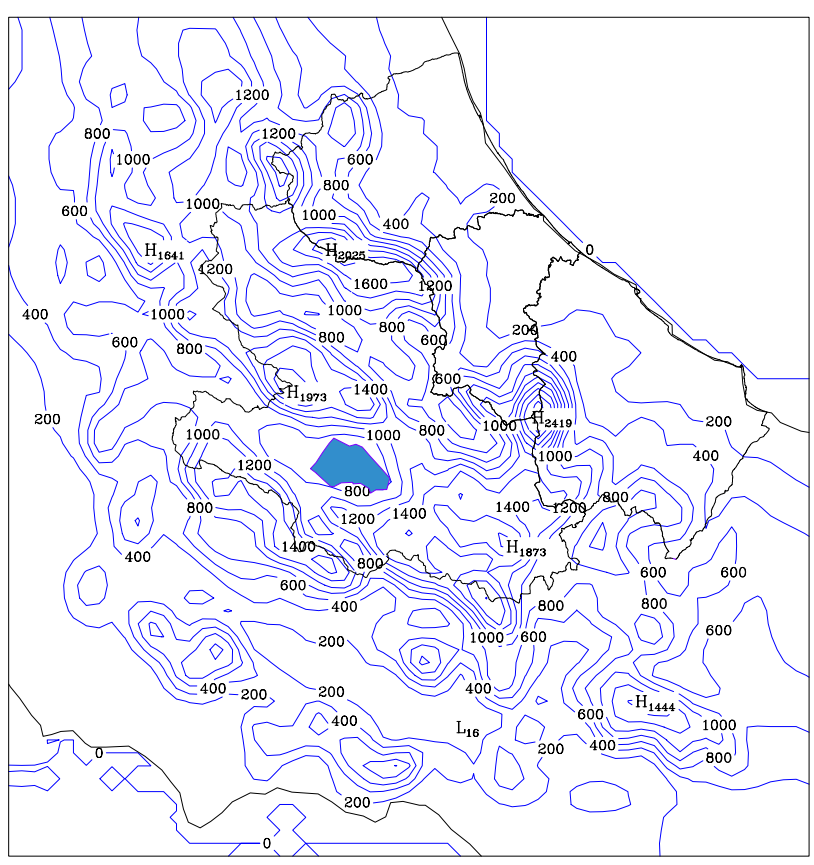

CONTOUR FROM 0 TO 2400 BY 200

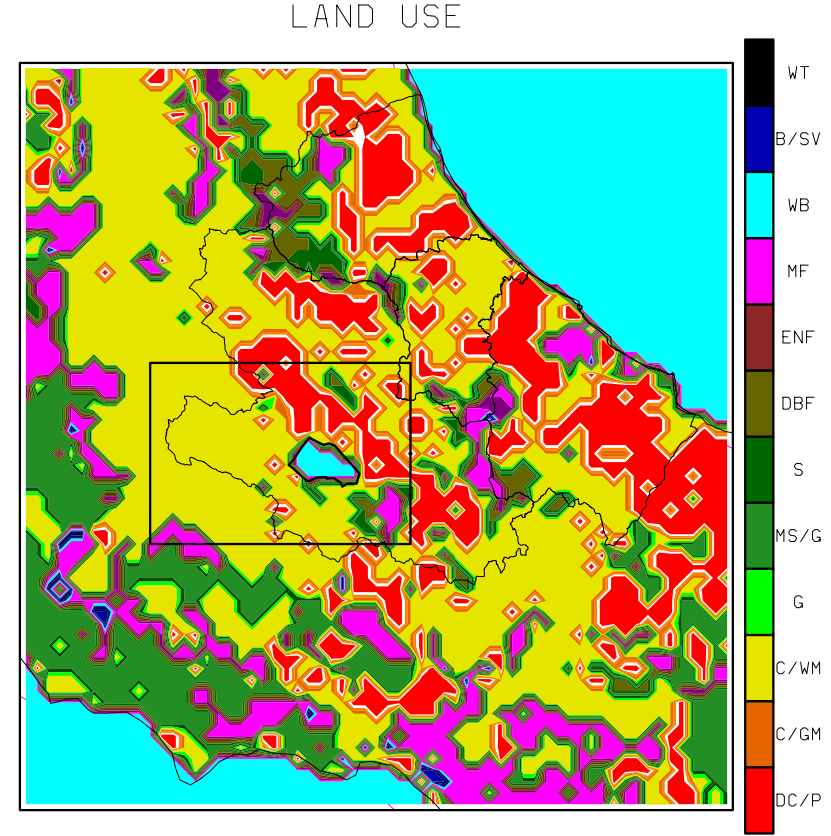

Fig. 2. Model topography (a) and land-use type (b) for the inner domain and area covered by the Fucino Lake (in blue). Units are $\mathrm{m}$ for topography. Also shown in Fig. $2 \mathrm{~b}$ is a sub-region surrounding the Fucino Lake used for the calculations reported in $\mathrm{Ta}$ ble 1. Land surface types in Fig. $2 b$ are: $D C / P=$ Dryland Cropland and Pasture; $\mathrm{C} / \mathrm{GM}=$ Cropland/Grassland Mosaic; $\mathrm{C} / \mathrm{WM}=$ Cropland/Woodland Mosaic; $\mathrm{G}=$ Grassland; MS/G = Mixed Shrubland/Grassland; $\mathrm{S}=$ Savannah; $\mathrm{DBF}=$ Deciduous Broadleaf Forest; $\mathrm{ENF}=$ Evergreen Needleleaf Forest $; \mathrm{MF}=$ Mixed Forest; $\mathrm{WB}=$ Water Bodies; B/SV = Barren or Sparsely Vegetated; WT = Wooded Tundra. 
SUMSF 24 July, $199912: \varnothing \varnothing$ GMT
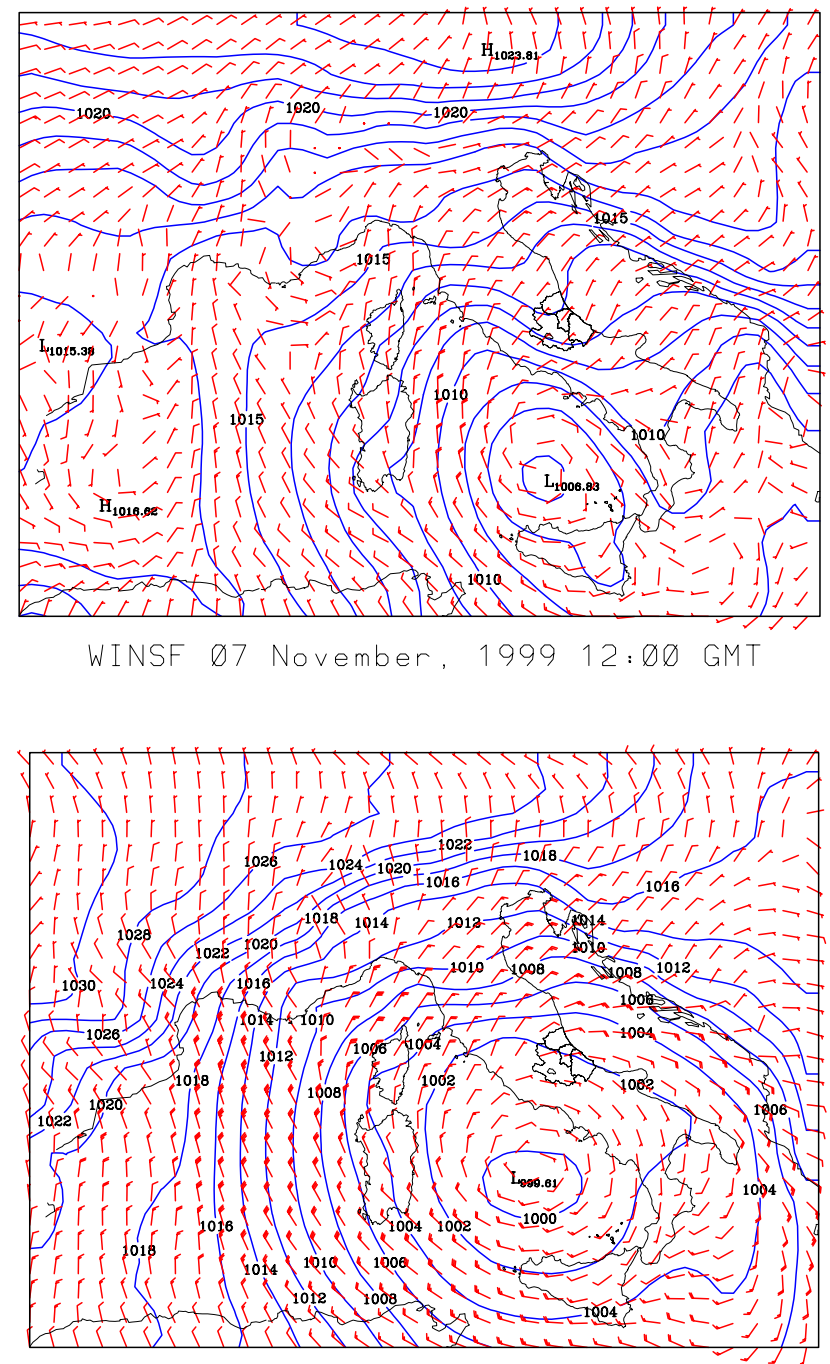

SUMWF $\varnothing 2$ JulY, $199912: \varnothing \varnothing$ GMT
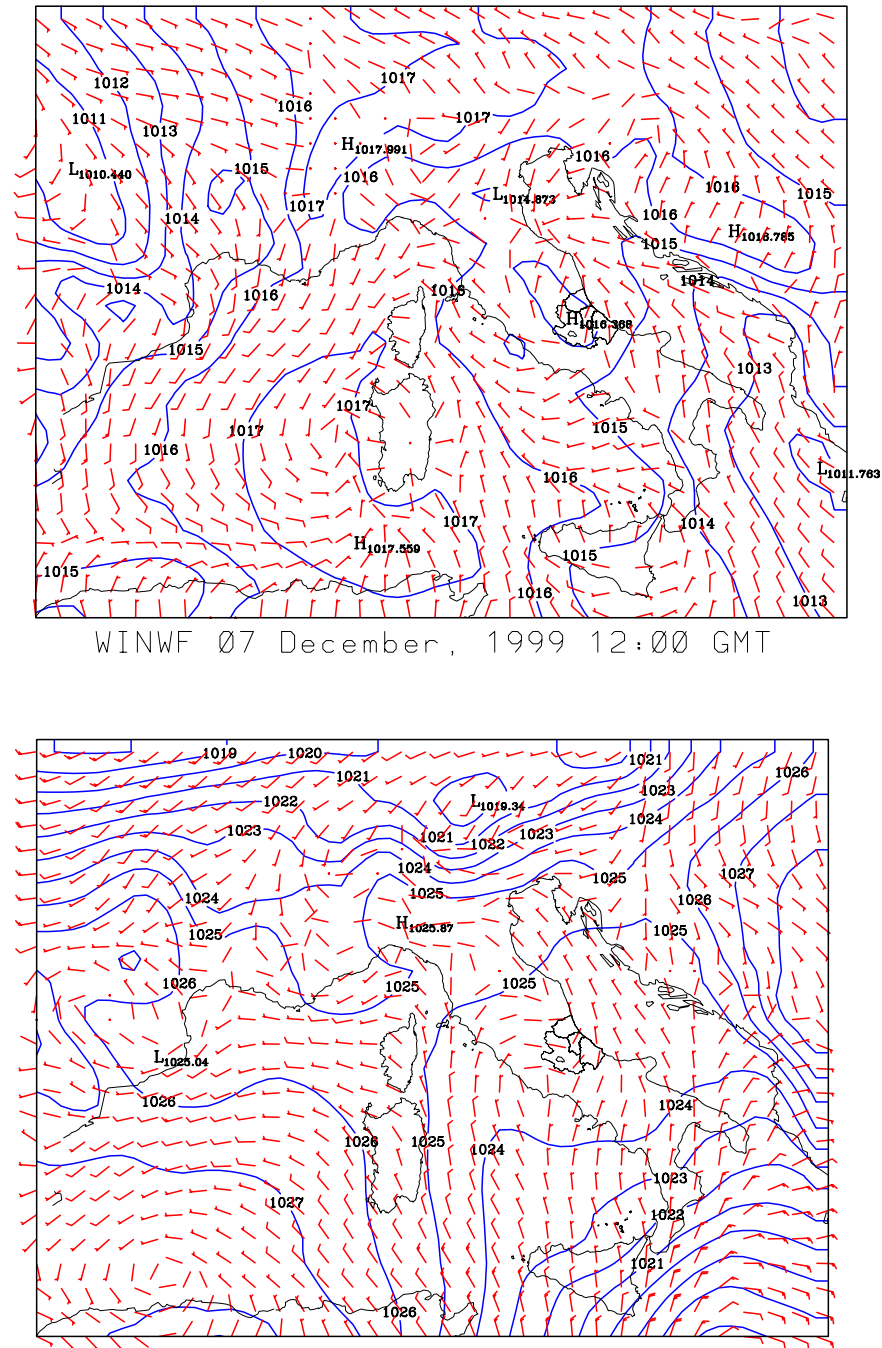

Fig. 3. Sea level pressure $(\mathrm{mb})$ and wind speed $(\mathrm{m} / \mathrm{s})$ and direction at given times within the four simulated cases. (a) Case SUMSF, $24 \mathrm{July}$ 1999, 12:00 GMT; (b) Case SUMWF, 02 July 1999, 12:00 GMT; (c) Case WINSF, 07 November 1999, 12:00 GMT; (d) Case WINWF, 07 December 1999, 12:00 GMT.

the present work and the short duration of the simulations we completed, use of a full lake model is left to the next stage of model development.

For our simulations we selected four cases, two for the summer season and two for the winter season. Each simulation is $48 \mathrm{~h}$ in duration. For each season, cases were selected which included strong atmospheric flow and intense precipitation (strong forcing) and weak atmospheric flow with little or no precipitation over the region (weak forcing). The summer strong forcing case (SUMSF) begins on 23 July 1999, at 12:00 GMT and shows a cyclonic circulation entering the Mediterranean area (Fig. 3a) and developing into a strong cyclogenesis over the southern Tyrrenian Sea. Strong easterly winds advecting warm and humid air toward the eastern Italian coasts produced heavy precipitation during this event. The summer weak forcing case (SUMWF) begins of 1 July 1999, 12:00 GMT and shows a typical anticyclonic system over the Mediterranean, characterized by weak southeasterly winds and little precipitation (Fig. 3b). The winter strong forcing case (WINSF) begins on 6 November 1999 , 12:00 GMT with a cyclonic system located over the Gulf of Genoa. During the next $48 \mathrm{~h}$ the system moves southeastward over the Tyrrenean Sea, producing strong northeasterly winds and widespread precipitation over the Italian peninsula and the Abruzzi region (Fig. 3c). Finally, the winter weak forcing case (WINWF) begins on 7 December 1999 , 12:00 GMT with a weak anticyclonic circulation and weak northerly winds over central Italy (Fig. 3d), persisting for the duration of the simulation period. The lake surface temperature for the four cases (see discussion above) is $20^{\circ} \mathrm{C}$ for 


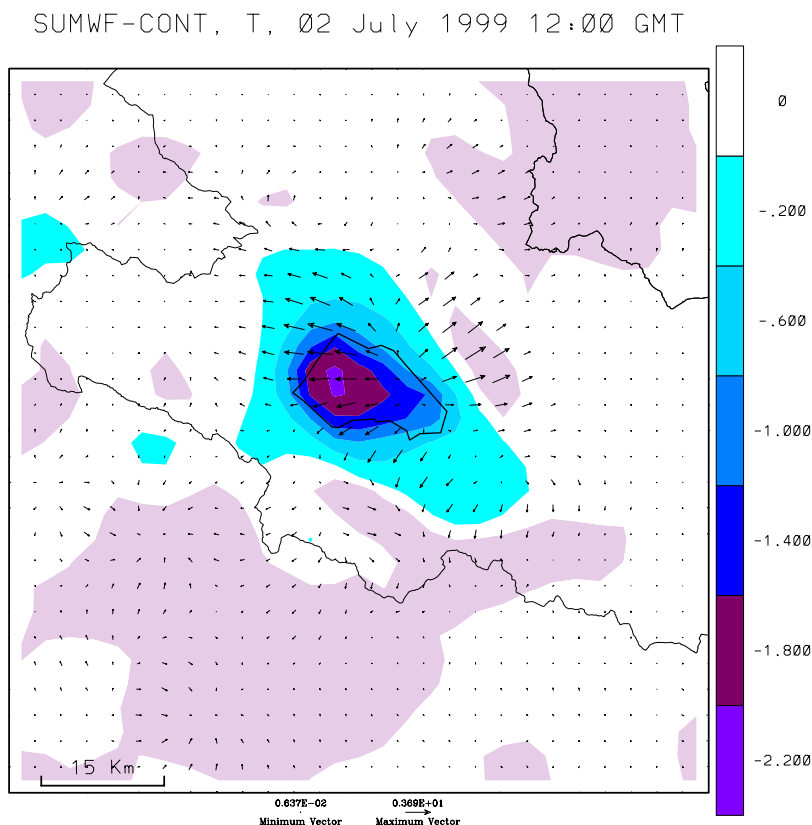

Fig. 4. Near surface temperature (color shading) and wind (arrows) difference between the SUMWF lake and corresponding no-lake cases at 02 July 1999, 12:00 GMT. Units are K for temperature and $\mathrm{m} / \mathrm{s}$ for wind speed.

\section{SUMSF, $24^{\circ} \mathrm{C}$ for SUMWF, $13^{\circ} \mathrm{C}$ for WINSF and $10^{\circ} \mathrm{C}$ for} WINWF.

For each case we completed simulations with and without the Fucino Lake. The experiments without the lake are here referred to as control (CONT) simulations. The analysis presented in the next sections examines the differences between the two sets of simulations which allow us to isolate the effects of the lake.

\section{Results}

\subsection{Dynamical effects}

The primary dynamical effect of lakes of the size of the $\mathrm{Fu}$ cino is to sustain mesoscale sea-breeze circulations due to the land-water gradient in atmospheric heating (e.g. Atkinson, 1981).

Figure 4 shows the low level (i.e. at $\sigma=1$, corresponding to a height of about $10 \mathrm{~m}$ from the surface) temperature and wind difference between the SUMWF (summer weak forcing case) and CONT experiments at 12:00 GMT of 2 July.

A temperature difference of $1-2 \mathrm{~K}$ between the lake and the surrounding land areas is observed which triggers onshore low level diverging winds of up to $4 \mathrm{~m} / \mathrm{s}$. Figure 5 shows the corresponding horizontal wind difference for an east-west cross section cutting across the lake. Two adjacent sea-breeze-like overturning cells can be observed to extend to about $700 \mathrm{mb}$. These are produced by the land-water thermal contrast and are then advected by the weak background winds. Similar sets of organized mesoscale circulations induced by patches of surface thermal inhomogeneities have been simulated in a number of previous studies, and have been shown to possibly affect precipitation under convectively unstable conditions (e.g. Pielke, 1974; Yan and Anthes, 1988; Pielke and Avissar, 1990; Seth and Giorgi, 1996; Giorgi and Avissar, 1997).

As a measure of the intensity of the overturning lake breeze circulation we calculated an index of breeze defined as

$\frac{1}{\Delta x} \oint\left(u_{l}-u_{c}\right) d x$

where $u_{c}$ and $u_{l}$ are the zonal wind for the control and lake cases, respectively; the integral is taken over a closed path that cuts across the lake from its center to the eastern coastal regions at two $\sigma$ levels, one close to the surface (i.e. $\sigma=$ 0.95 ) and one (in the opposite direction) at $\sigma=0.8$ (corresponding to $750-800 \mathrm{mb}$ over the Fucino basin), and $\Delta x$ is the horizontal length of this path. Figure 6 shows the time evolution of the breeze index for the summer cases.

In the SUMWF case a lake breeze develops through the afternoon of 2 July and the late stage of the breeze is also evident in the late afternoon hours of 1 July. Conversely, no signal of afternoon breeze is evident in the SUMSF case, with mostly random variations of this index throughout the simulation and relatively large values due to the stronger winds in this case. Observational and modeling experience has indeed shown that strong background winds tend to destroy the coherent nature of thermally-induced overturning mesoscale circulations (e.g. Atkinson, 1981; Seth and Giorgi, 1996). In addition, the breeze index did not show the formation of lake breezes in the winter cases (not shown), when the surface thermal forcing is less pronounced and the background winds are stronger than in summer. In Sect. 3.4 we will see how the lake breeze signal in experiment SUMWF is a robust feature of the simulation.

The results of Fig. 6 thus indicate that the model is able to simulate the realistic generation of lake breezes and their response to background atmospheric conditions.

\subsubsection{Thermo-dynamical effects}

Because of the difference between water and land thermal properties, it can be expected that lakes affect the temperature of the surrounding region (e.g. Changnon and Jones, 1972; Bates et al., 1993). In particular, because the heat capacity of water is greater than that of land, the lake temperature will in general be lower than the land temperature during the warm season, especially during the daytime, and higher during the cold season. As a result, lakes can be expected to provide a cooling effect during the summer and a warming effect during the winter. The magnitude of such an effect depends on the lake surface area and depth, as well as on the surrounding topographical features (e.g. Hostetler et al., 1994).

Figures 7 and 8 show the difference between the average surface air temperature in the lake and no-lake cases 


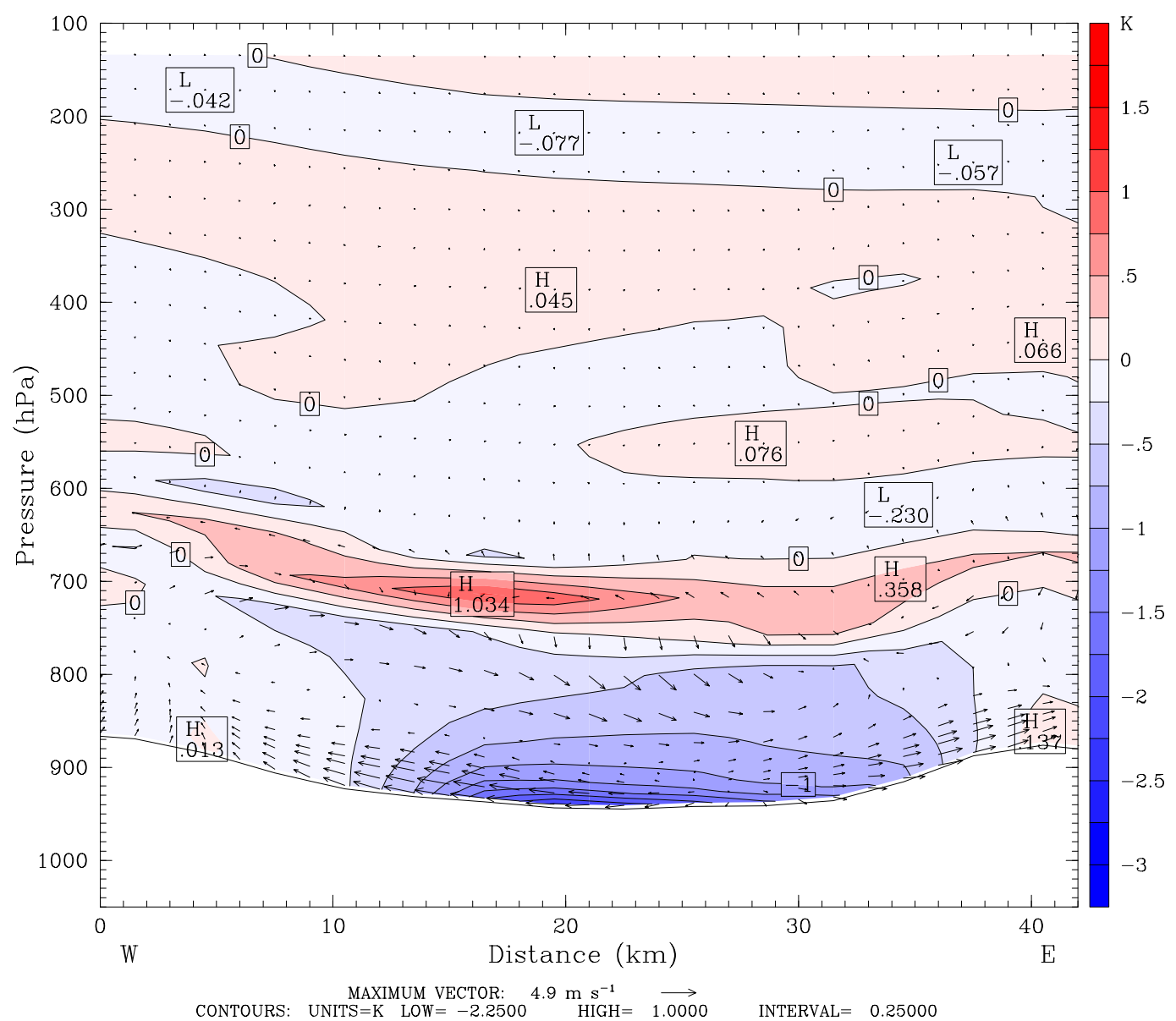

Fig. 5. East-west vertical cross section of wind difference between the SUMWF lake and corresponding no-lake case at 02 July 1999 , 12:00 GMT. The cross section is taken across the middle of the lake. Units are $\mathrm{m} / \mathrm{s}$.

for the daytime (08:00 GMT to 19:00 GMT) and nighttime (20:00 GMT to 07:00 GMT) conditions in the winter and summer experiments, respectively. The averages are calculated over both days of each simulation and only the region surrounding the Fucino Lake is shown. In the winter cases the lake-effect warming is evident both in the daytime and nightime averages, and both in the strong forcing and weak forcing cases. In the WINWF case the lake-induced warming reaches about $2 \mathrm{~K}$ during the daytime and over $3 \mathrm{~K}$ during the nighttime. The warming is maximum over the lake, but also extends over the land areas adjacent to the lake. In the case of the strong winter forcing (WINSF), the magnitude of the warming is reduced due to the dispersion by the more intense background winds, however, it still reaches about $1 \mathrm{~K}$ during the daytime and $1.5 \mathrm{~K}$ during the nighttime. In addition, because of the stronger background winds the lake-effect is felt at greater distances (several tens of $\mathrm{km}$ ) from the lake.

In the summer cases the interpretation of the results is more difficult. Previous regional modeling work (e.g. Giorgi and $\mathrm{Bi}, 2000)$ has shown that, especially during the summer, even small perturbations in the model fields can induce a noise-like response far from the origin of the perturbation. Therefore, for the summer cases it is difficult to at- tribute to the lake-effects the temperature response in the regions far from the lake, especially in the strong forcing case (SUMWF). The lake thermal effect is more evident in the summer weak forcing case (SUMWF), with a daytime cooling over the lake areas of up to about $-1 \mathrm{~K}$ and a nighttime warming greater than $1 \mathrm{~K}$.

Figure 9 shows vertical cross sections of the temperature difference between the SUMWF and CONT cases for an east-west transect across the whole Abruzzi region. The cross section is shown at 2 times, 12:00 GMT of 2 July (daytime) and 00:00 GMT of 2 July (nighttime). These figures illustrate the vertical propagation of the lake thermal effect. During the night, the stable boundary layer confines the lakeinduced warming to the lowest few hundred meters above the surface. Advection of this warming effect up the mountain slope downwind of the lake can also be observed. Conversely, during the daytime, when the boundary layer extends futher into the lower troposphere, the lake-induced cooling extends to over $1 \mathrm{~km}$ above the surface. Above the region of lake-induced cooling we find a region of warming which extends between about 750 and $650 \mathrm{mb}$. This can be attributed to the fact that the lake-effect cooling of the lower troposphere inhibits turbulence, and, therefore, in the lake exper- 


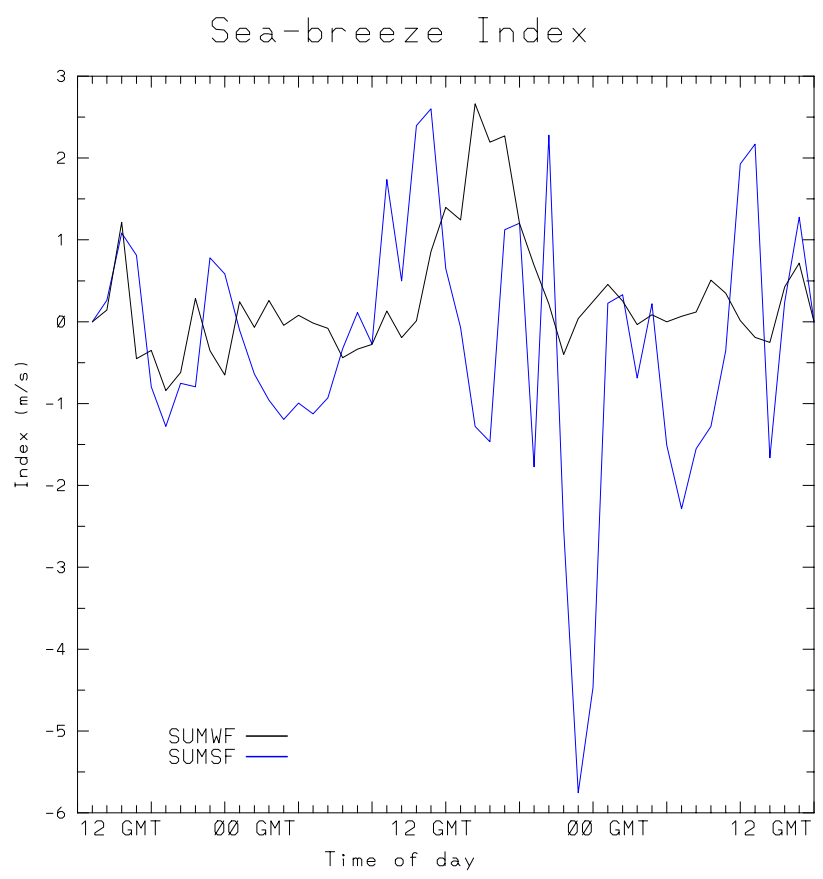

Fig. 6. Time evolution of sea-breeze index (see Eq. 1) for the SUMWF (black line) and SUMSF (blue line) cases. Units are m/s.

iments the depth of the boundary layer is lower than in the absence of the lakes. As a result, warming occurs in the detrainment regions close to the boundary layer top. Also note in Fig. 9 that some gravity wave structure appears in the lee of the mountain chain downwind of the lake. Figure 9 thus shows that the lake-effects can be seen a few $\mathrm{km}$ above the surface during the summer daytime and that the thermodynamical effects of the Fucino Lake are felt throughout the basin and over the surrounding topography.

During the wintertime (not shown), when stable conditions dominate, the lake-effect warming is mostly confined to the lower regions of the troposphere and it is also advected up the surrounding slopes.

\subsection{Effects on water vapor and precipitation}

The evaporation from inland bodies of water represents a source of moisture and moist static energy to the atmosphere, and as such can be expected to affect precipitation over the surrounding areas, especially in the presence of topographic forcing (Hostetler et al., 1994). Figure 10 shows the difference in low level atmospheric water vapor between the lake and no-lake experiments over the Fucino region.

In all cases the lake produces a general increase in water vapor loading over the area. In both the winter and summer weak forcing cases, when the background winds are relatively weak, the increase in water vapor is mostly concentrated over the Fucino basin, where a relatively large increase in water vapor is found. In the strong forcing cases the lake-moisture signal is more widespread and less evident. In fact, in the SUMSF experiment the lake signal is essen- tially masked by the noise generated by the model and in the WINSF case the increase is very small. Similarly to temperature, the lake-moisture signal extends to the lower boundary layer levels in the winter and further up in the summer (not shown for brevity).

The response of precipitation to the lake-moisture source is illustrated in Fig. 11, which shows the precipitation differences between the lake and no-lake experiments for the two strong forcing cases. Also shown in the figure are the corresponding precipitation amounts in the control (no lake) experiments. For the weak forcing cases little or no precipitation occurred over the Fucino area, and as a result little or no lake-effect precipitation was simulated. In the SUMSF case, a strong system with substantial precipitation affects the northeastern regions of the Abruzzi (Fig. 11a). The presence of the lake does affect some details of the spatial structure of precipitation (Fig. 11b), however, this effect cannot be easily attributable to the lake forcing.

In the winter strong forcing case the direct effect of the $\mathrm{Fu}$ cino Lake on the surrounding basin is more evident. In this case, an intense storm crosses the Tirrenean Sea and central Italy from the northwest to the southeast direction (see Figure 3c). This produces widespread and intense precipitation throughout the Abruzzi region (Fig. 11c). Two lake-effect precipitation areas can be observed to originate from the lake (Fig. 11d), a maximum southwest of the lake and one northeast of the lake. Comparison of the precipitation differences of Fig. 11d with the topography field of Fig. 2a, shows that these two areas of lake-effect precipitation occur in correspondence to mountain systems surrounding the lake. This indicates that the main process responsible for the lake-effect precipitation is the topographic uplift of relatively moist air downwind of the lake.

More specifically, the maximum northeast of the lake is caused by a southerly low level flow which prevails over central Italy during the early stages of the storm development in the northern Tirrenian Sea. As the storm moves southeastward during the second day of the simulated period, the prevailing low level flow over the Abruzzi region becomes northeasterly. This flow carries water vapor generated by the lake evaporation towards the southwest, which eventually precipitates as it flows up the topographic slope. Note that some of the lake-effect precipitation appears to also extend beyond the lake basin, up to a few tens of $\mathrm{km}$ from the lake.

In summary, the results discussed in this section indicate that the presence of the lake can affect both the atmospheric humidity and precipitation not only over the Fucino basin but also over broader areas of the Abruzzi region, especially when wintertime storms move across the area.

\subsection{Sensitivity experiments}

In order to test the robustness of our results we carried out a series of sensitivity experiments:

(i) As mentioned, the standard MM5 uses a surface typedependent moisture availability parameter $\left(A_{w}\right)$ to cal- 

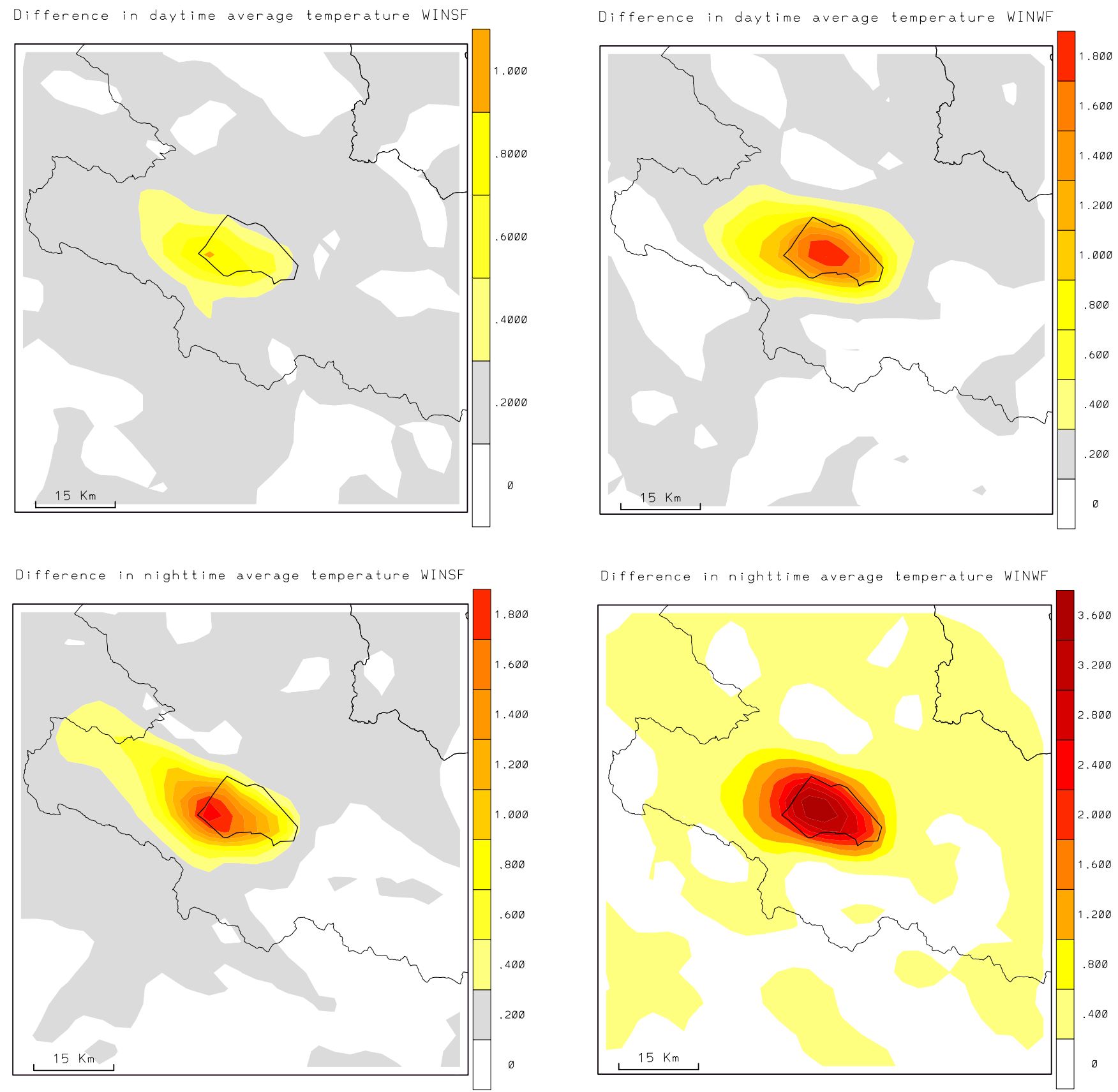

Fig. 7. Difference in daytime and nighttime average temperature between cases with the lake and without the lake. (a) WINSF, daytime; (b) WINWF, daytime; (c) WINSF, nighttime; (d) WINWF, nighttime. Units are K.

culate actual evaporation from potential evaporation. Since this affects the surface energy and water budget, it is possible that the model results depend on the values used for this parameter. For the surface types utilized in our simulations (see Fig. 2b) this parameter varies in the range of 0.3 to 0.6 for the winter cases and $0.15-0.3$ for the summer cases. We thus carried out two experiments, one in which $A_{w}$ is increased by $25 \%$ in each grid point of the inner domain (Exp. SW+) and one in which it is correspondingly decreased by $25 \%$ (Exp. SW-). (ii) A factor that can also affect the simulated results is the land-use type used in the no-lake cases over the lake area, since, for example, the sea breeze index is calculated as a residual between the lake and no-lake cases. In our experiments we used present day land use, mostly cropland, and we performed a sensitivity experiment (Exp. LANDUSE) in which cropland is changed into forest over the entire lake area.

(iii) Finally, another factor that can affect the simulations is the domain size. To test the importance of this factor we 
Difference in daytime average temperature SUMSF

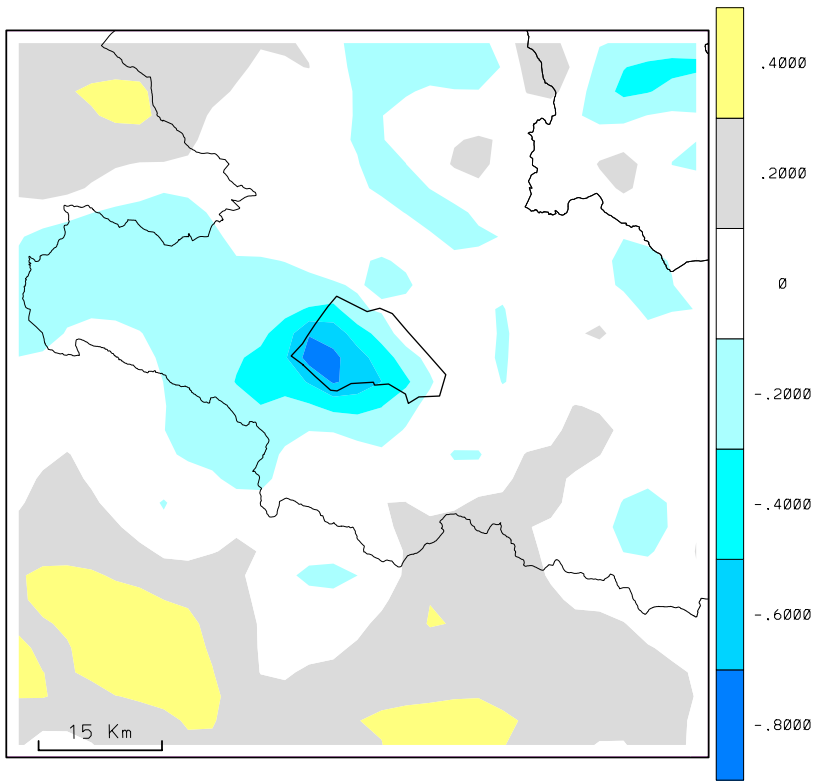

Difference in nighttime average temperature SUMSF

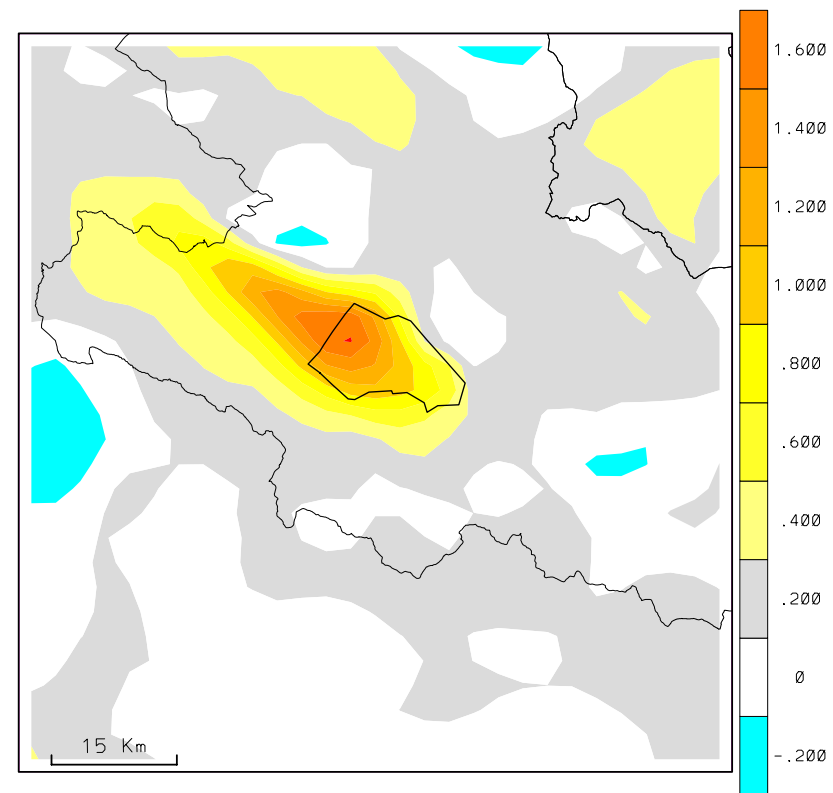

Difference in daytime average temperature SUMWF

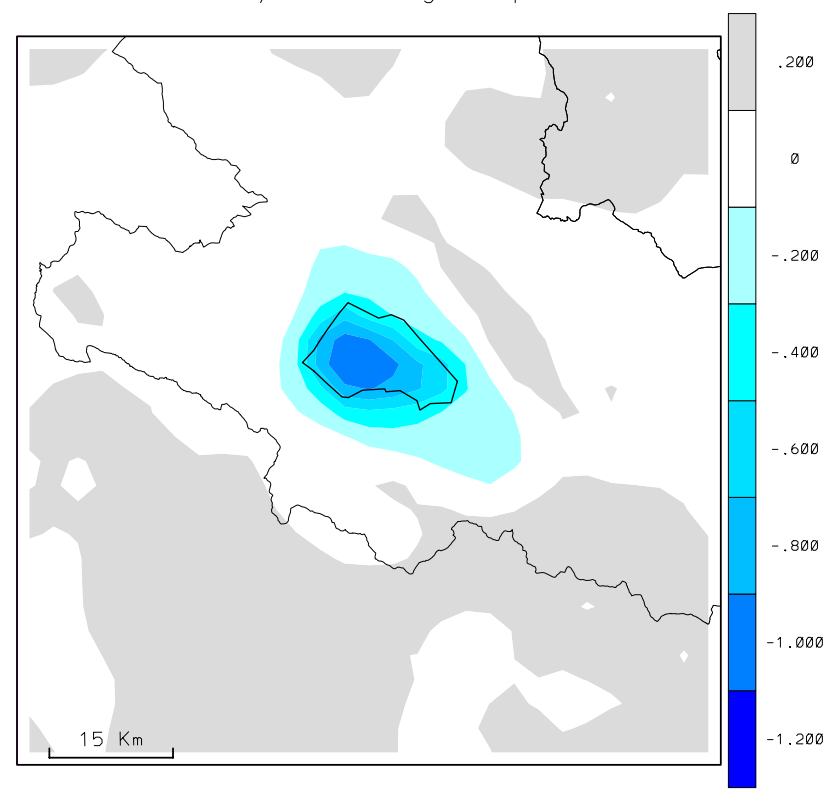

Difference in nighttime average temperature SUMWF

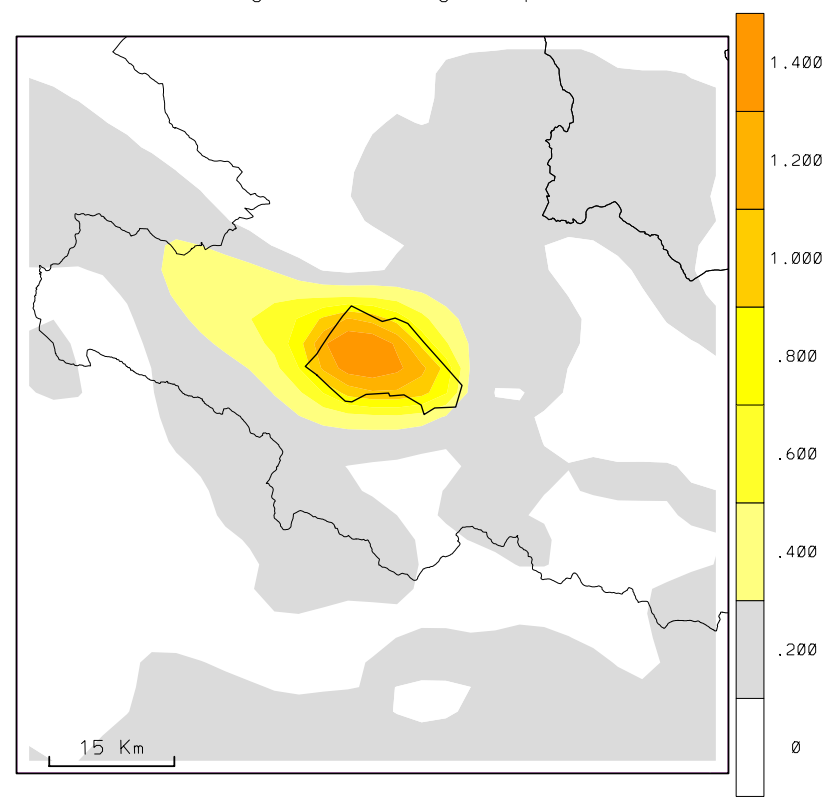

Fig. 8. Same as Fig. 7 but for the summer cases. (a) SUMSF, daytime; (b) SUMWF, daytime; (c) SUMSF, nighttime; (d) SUMWF, nighttime. Units are $\mathrm{K}$.

completed an experiment (Exp. DOMAIN) in which the inner domain was enlarged by $90 \mathrm{~km}$ (30 grid points) in each direction.

We carried out these sensitivity experiments for two of the four simulated cases, the case SUMWF, in which the lake breeze is most evident, and the case WINSF, in which the lake-effect precipitation is most evident. For each case, both the lake and no-lake simulations were completed.

Figure 12 shows the lake-breeze index calculated in the SUMWF case for the original run and all sensitivity experi- ments. All cases show a similar behavior, with a lake breeze developing in the afternoon of the second day of simulation. Even the intensity of the breeze is similar in all the sensitivity experiments, except for a somewhat stronger breeze developing in the SW+ experiment. Figure 12 thus shows that the development of a lake breeze is a robust feature in the model.

Table 1 shows the lake-induced changes in precipitation and surface air temperature (daytime and nighttime averages) over the area surrounding the lake Fucino basin (illustrated in Fig. 2b) for the original and all sensitivity experiments. Note that in the SUMWF case negligible precipitation was pro- 

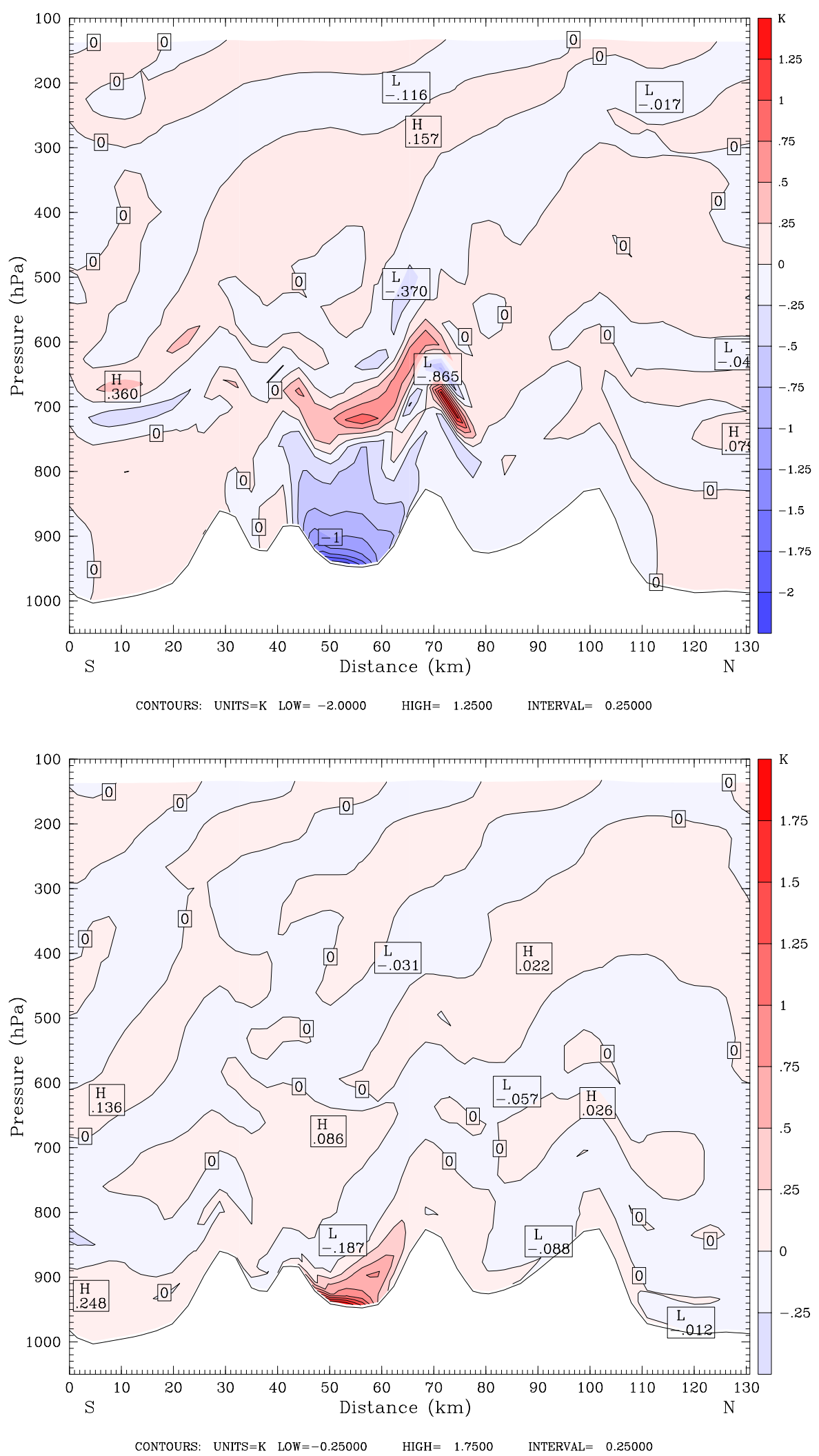

Fig. 9. East-west vertical cross section of temperature difference between the lake SUMWF experiment and the corresponding no-lake experiment at (a) 02 July 1999, 12:00 GMT (daytime), and (b) 02 July 1999, 00:00 GMT (nighttime) units are K. 

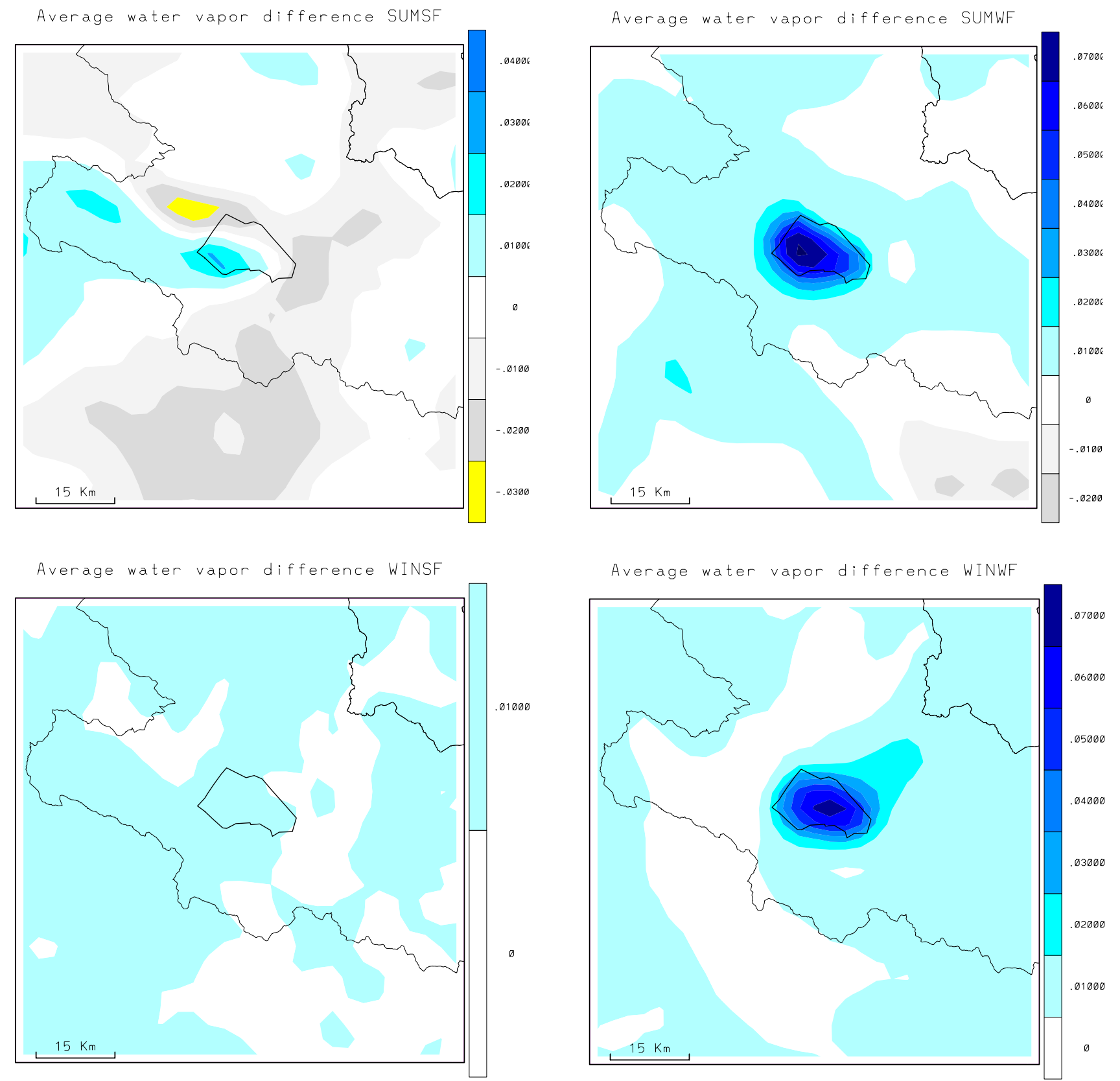

Fig. 10. Average water vapor difference between cases with the lake and without the lake. (a) SUMSF; (b) SUMWF; (c) WINSF; (d) WINWF. Units are $\mathrm{kg} / \mathrm{kg}$.

duced in all simulations over the basin. In all the WINSF sensitivity experiments the lake-effect precipitation areas northeast and southwest of the lake (see Fig. 11) were reproduced (not shown). In the original WINSF case the average lakeeffect precipitation in the sub-region surrounding the lake Fucino is about $0.8 \mathrm{~mm}$ for the 2 days. The increase in soil moisture availability (Exp. SW+) essentially does not significantly affect the simulated lake-effect precipitation. However, both the reduction of soil water availability (Exp. SW-) and the change in inner nested domain (Exp. DOMAIN), significantly decrease the lake-effect precipitation for this case.
Finally, the land-use change over the lake area produces a small decrease in lake-effect precipitation.

Table 1 also displays that the lake-effect temperature changes over the sub-region of Fig. $2 b$ show a low sensitivity to the parameter changes tested. In the WINSF case the average lake-effect change in daytime and nighttime temperature is in the range of $0.08-0.1 \mathrm{~K}$ and $0.17-0.19 \mathrm{~K}$, respectively. In the SUMWF case the lake-induced daytime cooling is in the range of -0.10 to $-0.13 \mathrm{~K}$, while the lake-induced nightime warming is in the range of 0.087 to $0.11 \mathrm{~K}$. 

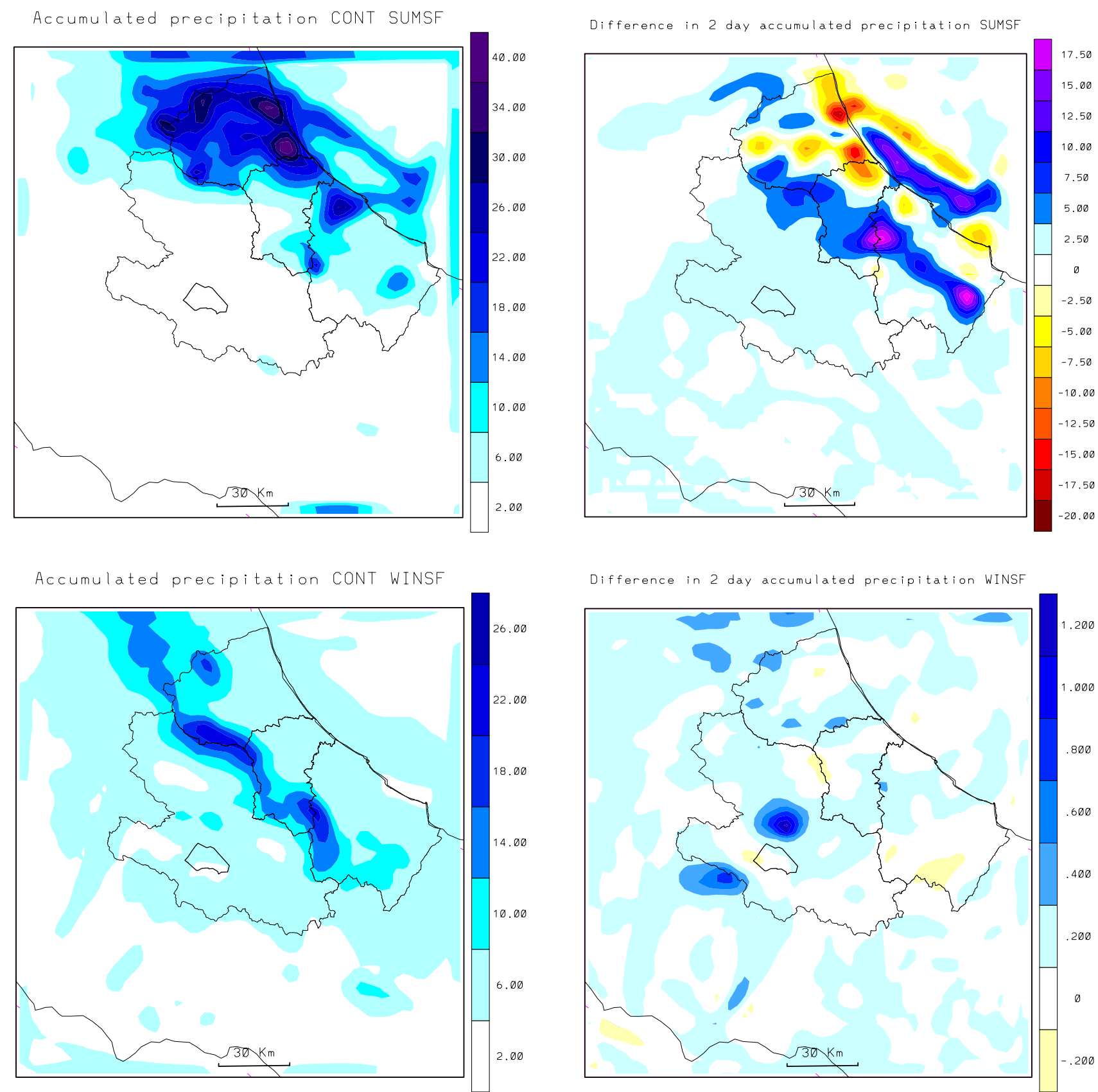

Fig. 11. Two-day accumulated precipitation in the control (CONT, no-lake) experiments and difference in 2-day accumulated precipitation between the lake experiment and the corresponding control experiment. (a) SUMSF, precipitation; (b) SUMSF, precipitation difference; (c) WINSF, precipitation; (d) WINSF, precipitation difference. Units are $\mathrm{cm}$.

Overall, our sensitivity experiments show that the basic conclusions regarding lake-effect simulation found in our experiments are not substantially modified within the range of parameters tested, although the magnitude of the lake-effect shows some sensitivity to these parameters.

\section{Summary and discussion}

The experiments discussed in this paper show that the triple-nested regional model configuration developed for the Abruzzi region is capable of simulating realistic lake-breeze circulations due to the presence of the lake Fucino. Previous work (e.g. Dalu et al., 1991) has shown that land surface thermal heterogeneities can induce sea-breeze-like mesoscale circulations with strength maximum at scales close to the lo- 


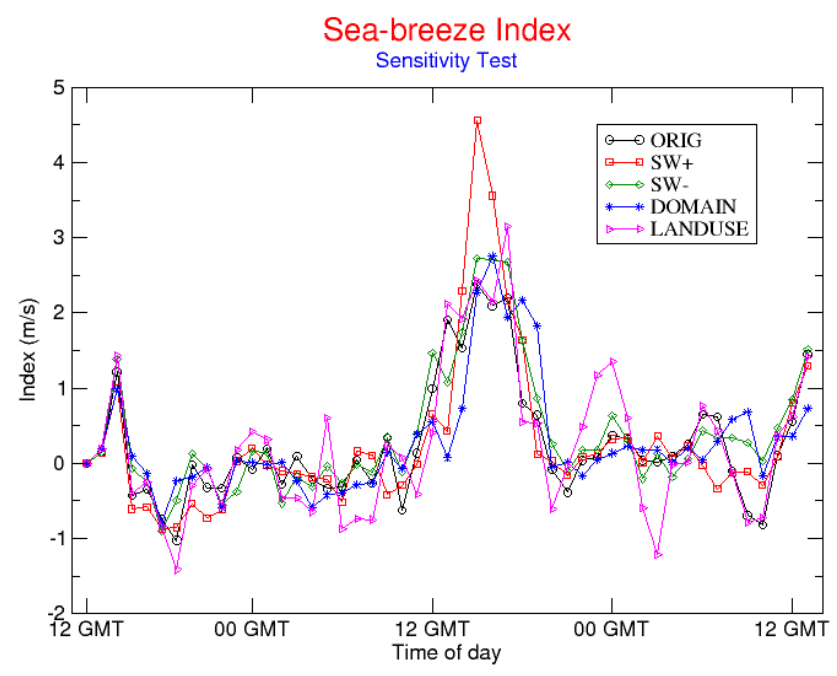

Fig. 12. Lake breeze index (see text) calculated for the original run (ORIG) and all the sensitivity experiments of the SUMWF case.

cal Rossby radius of deformation and rapid decaying with the intensity of the background flow. Our results are consistent with these findings in that much more intense lake-breeze circulations develop in the weak forcing summer cases than in the strong forcing cases.

The simulations indicate that the lake can affect the temperature of the surrounding basin in all seasons and the precipitation in the cold season, especially when cyclonic perturbations move across the region. In this regard, we should point out that the specific location of these lake hydrometeorological effects may depend on the model resolution and the resulting representation of the lake surface and the surrounding mountain chains. On the other hand, a set of sensitivity experiments carried out to test the effect of soil water content, inner domain size and land-use type in the lake area did not strongly modify the simulation of lake-effects, so that our basic conclusions are deemed to be robust.

Our results thus suggest that the draining of the Fucino Lake might have caused significant hydrometeorological effects over the surrounding basin and possibly over more extended areas of the Abruzzi region. The regional model developed for the region appears capable of describing such effects, however, a number of improvements are necessary in order to achieve a more quantitative and statistically robust assessment of them.

First, the present version of the MM5 does not include interactive soil moisture calculations, and thus cannot be applied to long-term climate simulations. A more detailed land surface scheme which includes interactive soil moisture calculations has recently become available as an option for use in MM5 (e.g. Chen and Dudhia, 2001a, b), and we are currently in the process of testing it within our modeling system. Second, in the present experiments we used specified lake surface temperatures estimated from data for other lakes of the region. We plan to improve this aspect of the model by coupling to the MM5 an interactive one-dimensional lake
Table 1. Lake minus no-lake average precipitation (PREC), daytime temperature (T-DAY) and nighttime temperature (T-NIGHT) over the subregion surrounding the Fucino Lake shown in Fig. 2 for the original simulation (ORIG) and the sensitivity experiments of the cases SUMSF and WINSF

\begin{tabular}{clll}
\hline & \multicolumn{3}{l}{ WINSF } \\
\hline & PREC $(\mathrm{cm})$ & T-DAY $(\mathrm{K})$ & T-NIGHT (K) \\
\hline ORIG & 0.081 & 0.083 & 0.170 \\
SW+ & 0.087 & 0.100 & 0.170 \\
SW- & 0.041 & 0.085 & 0.180 \\
DOMAIN & 0.027 & 0.081 & 0.190 \\
LANDUSE & 0.073 & 0.088 & 0.180 \\
\hline & & SUMWF & \\
\hline & PREC (cm) & T-DAY (K) & T-NIGHT (K) \\
\hline ORIG & 0.000 & -0.110 & 0.090 \\
SW+ & 0.000 & -0.130 & 0.110 \\
SW- & 0.000 & -0.110 & 0.087 \\
DOMAIN & 0.000 & -0.100 & 0.087 \\
LANDUSE & 0.000 & -0.120 & 0.093 \\
\hline
\end{tabular}

model (Hostetler and Bartlein, 1990; Small et al., 1999). Once these model improvements are fully implemented and tested we plan to conduct long-term multi-year simulations to study in more quantitative and statistically robust terms the possible climatic effects of the draining of the Fucino Lake.

Acknowledgements. We would like to acnowledge the contribution by Rossella Ferretti and Tiziana Paolucci to an early phase of this research. This work as been carried out on CETEMPS funds.

Topical Editor J. P. Duvel thanks R. Arritt and another referee for their help in evaluating this paper.

\section{References}

Assouline, S. and Mahrer, Y.: Spatial and temporal variability in microclimate and evaporation over lake Kinneret: Experimental evaluation, J. Appl. Meteorol., 35, 1076-1084, 1995.

Atkinson, B. W.: Meso-scale atmospheric circulations, Academic Press , London, 412 pp, 1981.

Avissar, R. and Pan, H.: Simulation of the summer Hydrometeorological Processes of Lake Kinneret, J. Hydrometeorol., 1, 95109, 2000.

Bates, G. T., Giorgi, F., and Hostetler, S. W.: Towards the simulation of the effects of the Great Lakes on regional climate, Monthly Weather Review , 121, 1373-1387, 1993.

Bitan, A.: The wind regime in the North-West section of the Dead Sea, Arch. Met. Geoph. Biokl., Ser. B, 22, 313-335, 1974.

Brisse, A. and De Rotrou, G.: Il prosciugamento del lago Fucino. Descrizione storica e tecnica, vol.1 , Tipografia Poliglotta, Roma, 322 pp, 1883.

Burri, E.: Sulle rive della memoria - Il lago Fucino e il suo Emissario, Carsa Edizioni, Avezzano, Italy, 85 pp, 1994.

Changnon, S. A., Jones, D. M. A., et al.: Review of the influences of the Great Lakes on Weather. Water Resour. Res., 8, 360-371, 1972. 
Chen, F. and Dudhia, J.: Coupling an advanced landsurface/hydrology model with the Penn State/NCAR MM5 modeling system, Part I: Model implementation and sensitivity, Mon. Wea. Rev., 129, 569-585, 2001a.

Chen, F. and Dudhia, J.: Coupling an advanced landsurface/hydrology model with the Penn State/NCAR MM5 modeling system, Part II: Preliminary model validation, Mon. Wea. Rev., 129, 586-602, 2001b.

Dalu, G. A., Pielke, R. A., Avissar, R., Kallos, G., Baldi, M., and Guerrini, A.: Linear impact of thermal heterogeneities on mesoscale atmospheric flow with zero synoptic wind, Ann. Geophysicae, 9, 641-647, 1991.

Dudhia, J.: A nonhydrostatic version of the Penn State/NCAR mesoscale model: Validation test and simulation of an Atlantic cyclone and cold front, Mon. Wea. Rev., 121, 493-1513, 1993.

Eichenlaub, V. L.: Weather and Climate of the Great Lakes Region, The University of Notre Dame Press, Notre Dame, 335 pp., 1979.

Giorgi, F. and Bi, X.: A study of internal variability of a regional climate model, J. Geophys. Res., 105, 29 503-29 521, 2000.

Giorgi, F. and Avissar, R.: The representation of heterogeneity effects in earth system modeling: Experience from land surface modeling, Rev. Geophys., 35, 413-438, 1997.

Giraudi, C.: The Late Pleistocene and Holocene Temporary Lakes in the Abruzzo Parks and the Central Apennines, Global Change and Protected Areas, Kluwer Academic Publishers, 445-458, 2001.

Grell, G. A., Dudhia, J., and Stauffer, D. R.: A Description of the fifth generation Penn State/NCAR Mesoscale Model (MM5), NCAR Technical Note, NCAR/TN-398+STR, 121 pp., 1994.

Hostetler, S. W. and Bartlein, P. J.: Simulation of lake evaporation with application to modeling lake-level variations at HarneyMalheur Lake, Oregon. Water Resour. Res., 26, 2603-2612, 1990.

Hostetler, S. W., Giorgi, F., Bates, G. T., and Bartlein, P. J.: The role of lake-atmosphere feedbacks in sustaining paleolakes Bon- neville and Lahontan 18000 years ago, Science, 263, 665-668, 1994.

Kain, J. S. and Fritsch, J. M.: A one-dimensional entraining/detraining plume model and its application in convective parameterization, J. Atmos. Sci., 47, 2784-2802, 1990.

McGowan, H. A., Owens, I. F., and Sturman, A. P.: Thermal and dynamic characteristics of alpine lake breezes, Lake Tekapo, New Zealand, Boundary-Layer Meteorol., 76, 3-24, 1995.

Paolucci, T., Bernardini, L., Ferretti, R., and Visconti, G.: MM5 Real-Time Forecast of a Catastrophic Event on May, 5 1998, Il Nuovo Cimento, 12, 727-736, 1999.

Pielke, R. A.: A three-dimensional numerical model of the seabreeze over south Florida, Mon. Wea. Rev., 102, 115-139, 1974.

Pielke, R. and Avissar, R.: Influence of landscape structure on local and regional climate, Landscape Ecology, 4, 133-155, 1990.

Ruggeri, M.: Studio degli effetti climatici localli indotti dal prosciugamento del lago del Fucino, Tesi di Laurea, Istituto di Fisica, Universita' degli Studi di Roma, 122 pp, 1982.

Seth, A. and Giorgi, F.: A three-dimensional model study of organized mesoscale circulations induced by vegetation, J. Geophys. Res., 101, 7371-7392, 1996.

Small, E. E., Sloan, L. C., Hostetler, S., and Giorgi, F.: Simulating the water balance of the Aral Sea with a coupled regional climate-lake model, J. Geophys. Res., 104, 6583-6602, 1999.

Troen, I. and Mahrt, L.: A simple model of the atmosphere boundary layer: sensitivity to surface evaporation, Bound.-Layer Meteor., 37, 129-148, 1986.

Yan, H. and Anthes, R. A.: The effect of variation in surface moisture on mesoscale circulations, Mon. Wea. Rev., 116, 192-208, 1988.

Zhang, D. L., Chang, H. R., Seaman, N. L., Warner, T. T., and Fritsch, J. M.: A two-way interactive nesting procedure with variable terrain resolution, Mon. Wea. Rev., 114, 1330-1339, 1986. 